\title{
Supplementation of Seminal Plasma-Heparin Binding Proteins to Capacitation Medium Increases In Vitro Acrosome Reaction Percentage in Beetal Bucks
}

\author{
Navjot Singh Dhillon and Ranjna S Cheema* \\ Department of Veterinary Gynecology and Obstetrics, Guru Angad Dev Veterinary and Animal Sciences \\ University, Ludhiana, Punjab, India \\ *Corresponding author: ranjna.cheema@gmail.com
}

\begin{abstract}
This study was focused evaluating the effect of heparin binding proteins (HBP) on in vitro capacitation and acrosome reaction (AR) in Beetalbucks. HBP were purified from pooled seminal plasma of six bucks to evaluate their effect on in vitro capacitation. Semen, washed twice with TALP medium was incubated in TALP, supplemented with glucose, BSA, heparin and HBP for $6 \mathrm{hrs}$ at $37^{\circ}$. A control was also run without HBP. Incubated samples were evaluated for motility, viability, acrosome reaction and inner mitochondrial membrane potential (IMMP) after every $2 \mathrm{hrs}$. Standardization of HBP concentration on in vitro acrosome reaction revealed $150 \mu \mathrm{g} / \mathrm{ml} \mathrm{HBP}$ as an optimum dose. Based on sperm parameters, six bucks were divided into two groups i.e. G-I (> $80 \%$ motility) and G-II $(<$ $80 \%$ motility).There was a significant $(\mathrm{p}<0.05)$ decrease in individual motility, viability and high IMMP from zero to six hrs of incubation in both control and HBP treated samples of both groups. A significant $(\mathrm{p}<0.05)$ increase in acrosome reaction and medium IMMP was noticeable in control and HBP treated samples with an increase in incubation time. In Vitro induced AR was also significantly $(\mathrm{p}<0.05)$ higher in HBP treated samples compared to control in both groups at $4 \mathrm{hrs}$ and $6 \mathrm{hrs}$ of incubation. However, Effect of buck on in vitro capacitation and AR was noticeable in both control and HBP treated samples of G-I and G-II. A non-significant ( $>>0.05)$ increase in LPO during capacitation and AR was also observed. This study concluded that SP-HBP enhanced the rate of in vitro AR in beetal bucks.
\end{abstract}

Keywords: Beetal bucks, Spermatozoa, Heparin binding proteins, Capacitation, Acrosome reaction

Seminal plasma (SP) includes many proteins that bind to heparin and related to glucosaminoglycans (GAGs). Heparin binding proteins (HBPs), synthesized in male accessory sex glands,transferred into secretions, bind to spermatozoa at ejaculation and play a vital role during fertilization processes. They interact with GAGs present in the female genital tract and enhance the subsequent zona pellucidainduced acrosome reaction (AR) and are correlated with fertility in some species. Heparin binds to spermatozoa of several mammals in a $\mathrm{pH}-, \mathrm{Ca}^{+2}$, and temperature-dependent manner which is needed for the initiation of in vitro capacitation, and also enhances sperm motility and AR (Cormier et al., 2003; PonsRejraji et al., 2009). There are studies that indicate that heparin alone cannot capacitate epididymal spermatozoa and regulate other steps of fertilization. However, when accessory glands proteins (HBPs) are added to epididymal

How to cite this article: Dhillon, N.S. and Cheema, R.S. (2020). Supplementation of seminal plasma-heparin binding proteins to capacitation medium increases in vitro acrosome reaction percentage in beetal bucks. Theriogenology Insight, 10(1): 07-15.

Source of Support: None; Conflict of Interest: None 
spermatozoa, they undergo capacitation and zona pellucida induced AR is potentiated (Miller et al., 1990). SP proteins that bind heparin may be directly involved in sperm capacitation and AR (two essential steps for mammalian fertilization). HBPs also help spermatozoa to face the stress challenge by lysophosphatidyl-choline and undergo the AR (Lane et al., 1999). HBPs play pivotal role in spermatozoa survival and overall fertilization process, and any impairment in these proteins might be directly or indirectly related to infertility. Sperm capacitation is pre-requisite for acrosome reaction (AR) and potentially enhanced by glycosaminoglycans (GAG) and heparin. Heparin binding proteins in seminal plasma (SP-HBP) are supposed to attach themselves to the sperm surface, especially lipids containing the phosphorylcholine group, thus allowing heparin-like GAGs in the female reproductive tract to activate sperm capacitation (Miller et al., 1990). Addition of HBP to epididymal -, ejaculated spermatozoa induced heparin-stimulated acrosome reaction (Miller et al., 1990; Singh et al., 2016). Keeping in mind the importance of HBP in fertilization processes including capacitation in mammals, this study was aimed to evaluate the effect of SP-HBP on in vitro capacitation and AR in Beetal bucks.

\section{MATERIALS AND METHODS}

\section{Procurement of semen samples}

All the procedures were approved by Institutional ethical committee (GADVASU/2018/IAEC/ 46/06). Semen was collected twice a week using goat artificial vagina (IMV technologies) from six bucks, maintained at Goat Research Farm, Department of Livestock Production and Management, College of Veterinary Sciences, Guru Angad Dev Veterinary and Animal Sciences University, Ludhiana 141004, Punjab, India.

\section{Experimental design}

HBP were purified from pooled SP of six bucks. In the first experiment, optimum dose of HBP was established. In the second experiment, effect of optimum dose of HBP was evaluated in in vitro capacitation of six bucks.

\section{Purification of HBP by affinity chromatography}

HBP from SP were purified by affinity chromatography (Manaskova et al., 2002) using cyanogen bromide activated heparin bound sepharose (Farooqui, 1980). A clean and dry column $(28 \mathrm{~mm} \times 70 \mathrm{~mm})$ was packed with heparin-sepharose up to the mark at the top of the column and allowed to settle for 3-4 hrs. Thereafter, the column was equilibrated for $1 \mathrm{hr}$ with $10 \mathrm{mM}$ Tris $\mathrm{HCl}$ (pH 7.4). About $0.5 \mathrm{ml}$ of SP was loaded and circulated through the column for $15 \mathrm{~min}$ for absorption of HBP to the heparin bound resins. HBP peak was eluted with $1 \mathrm{M}$ $\mathrm{NaCl}$ at a flow rate of $1 \mathrm{ml} / \mathrm{min}$ in the tubes racked in a fraction collector. The recovered HBP fraction was pooled in agreement with the observed curve, obtained from optical density $(280 \mathrm{~nm})$ detected by UV monitor attached to the fraction collector (Fig. 1).

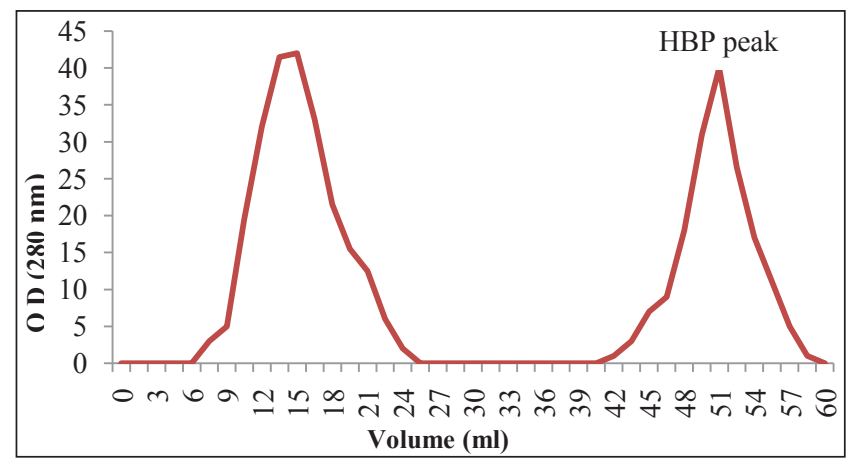

Fig. 1: Heparin-Sepharose affinity chromatography of seminal plasma.

The pooled HBP fraction was concentrated by spinning through protein concentrators (Millipore, $3 \mathrm{kDa}$ ) and analyzed for protein 
content (Lowry et al., 1951). Concentrated HBP fraction was mixed with glycerol @ 25\% and stored at $-20^{\circ}$ till further use.

\section{Semen analysis}

Three ejaculates of six bucks were analyzed for initial motility, viability, plasma membrane integrity and acrosome integrity prior to induction of in vitro acrosome reaction (Dhillon et al., 2019). Therefore, based on these parameters, bucks were divided into two groups i.e. G-I (> 80\%) and G-II (< 80\%).

\section{Effect of HBP on capacitation/acrosome reaction}

Basic TALP medium: $4.78 \mathrm{mM} \mathrm{NaCl}, 25 \mathrm{mM}$ $\mathrm{NaHCO}_{3}, 5.9 \mathrm{mM} \mathrm{Na}_{2} \mathrm{HPO}_{4}, 1 \mathrm{mM} \mathrm{CaCl}{ }_{2} .2 \mathrm{H}_{2} \mathrm{O}$, $1.19 \mathrm{mM} \mathrm{MgSO}, 1 \mathrm{mM}$ sodium pyruvate, $25 \mathrm{mM}$ sodium lactate. All ingredients were dissolved in $\mathrm{DW}$, and $\mathrm{pH}$ was set at 7.4 and final volume was made to $100 \mathrm{ml}$. Energy medium: Basic TALP medium supplemented with $5.56 \mathrm{mM}$ glucose, $20 \mathrm{mg} / \mathrm{ml} \mathrm{BSA}, 50 \mu \mathrm{g} / \mathrm{ml}$ gentamycin and $10 \mu \mathrm{g} / \mathrm{ml}$ heparin.

In first experiment, fresh semen was divided into four fractions $(200 \mu \mathrm{l}$ each); Ist fraction was kept as control and $100 \mu \mathrm{g}, 150 \mu \mathrm{g}$ and $200 \mu \mathrm{g} / \mathrm{ml}$ of HBP were added to the IInd, IIIrd and IVth fractions, respectively. Samples were incubated at $37^{\circ} \mathrm{C}$ for $10 \mathrm{~min}$. Energy TALP was added to the sperm suspensions, mixed gently and centrifuged at $3000 \mathrm{rpm}$ for $3 \mathrm{~min}$. This step was repeated twice and finally pellet of each fraction was gently mixed with energy TALP and energy TALP+ respective HBP dose to get a final sperm concentration of $200 \times 10^{6}$ sperms $/ \mathrm{ml}$. Control as well as HBP treated semen was incubated at $37^{\circ} \mathrm{C}$ for $6 \mathrm{hrs}$. Semen was checked for motility pattern every $2 \mathrm{hrs}$. A smear was also prepared at $0 \mathrm{hr}, 4 \mathrm{hrs}$ and 6 hrs, stained with giemsa and assessed for AR. In the second experiment semen of each buck was divided into two fractions (control and HBP treated) and processed as in experiment I. In addition to motility and acrosome reaction, viability (Eosin-Nigrosin stain) and inner mitochondrial membrane potential (IMMP) (JC1 stain kit, Sigma -Aldrich) were also evaluated at $0 \mathrm{hr}, 4 \mathrm{hrs}$ and $6 \mathrm{hrs}$.

Lipid peroxidation in capacitated spermatozoa (LPO, Buegeand Steven, 1978)

Capacitated spermatozoa after $6 \mathrm{hrs}$ were also subjected to LPO estimation. Sperm suspension was incubated with $0.1 \mathrm{ml}$ of $150 \mathrm{mM}$ Tris $\mathrm{HCl}$ $(\mathrm{pH} 7.1)$ at $37^{\circ} \mathrm{C}$ for $20 \mathrm{~min}$. After incubation, $0.5 \mathrm{ml}$ of $10 \%$ Trichloroacetic acid and 1.0 $\mathrm{ml}$ of $0.375 \%$ Thiobarbituric acid were added and kept for $20 \mathrm{~min}$ in the boiling water bath. Thereafter, mixture was centrifuged for $15 \mathrm{~min}$ at $5000 \mathrm{rpm}$ and absorbance of supernatant was taken at $532 \mathrm{~nm}$. The molar extinction coefficient for (Malondialdehyde) MDA is $1.56 \times$ $10^{5} \mathrm{M}^{-1} \cdot \mathrm{cm}^{-1}$.

$\operatorname{MDA}(\mu \mathrm{M})=$

OD $\times$ Volume of assay mixture $\times$ Extinction coefficient

Volume of sample

\section{STATISTICAL ANALYSIS}

The mean and standard error were calculated using Microsoft excel program. Significant differences in control and HBP treated groups were tested by ANOVA using SPSS16 program (Student version for windows, SPSS Inc.233 South Wacker Drive, $11^{\text {th }}$ floor Chicago, IL 60606-6412). Normality of the data was assessed using the Shapiro-Wilk test and homogeneity of variances was evaluated using the Levene test.

\section{RESULTS AND DISCUSSION}

Standardization of SP-HBP concentartion for in vitro capacitation /AR

Acrosome reaction (vessiculation + shedding) was significantly $(\mathrm{p}<0.05)$ higher in the presence of $150 \mu \mathrm{g} / \mathrm{ml} \mathrm{HBP}$ as compared to control and other doses (Table 1). However, motility was 
non-significantly $(\mathrm{p}>0.05)$ less in the presence of $200 \mu \mathrm{g} / \mathrm{ml} \mathrm{HBP}$ as compared to control and other doses. Therefore, effect of $150 \mu \mathrm{g} / \mathrm{ml} \mathrm{HBP}$ was analyzed on in vitro capacitation/AR of six bucks.

Table 1: Effect of different doses of SP-HBP on motility and acrosome reaction after six hours of incubation at $37^{\circ}$.

\begin{tabular}{ccccc}
\hline Attribute & Control & $\mathbf{1 0 0}$ & $\mathbf{1 5 0}$ & $\mathbf{2 0 0}$ \\
\hline Acrosome Reaction & $46.4 \pm 11.5$ & $34.6 \pm 5.8$ & $56.4 \pm 1.3$ & $46.5 \pm 2.0$ \\
Motility & $55.1 \pm 2.7$ & $53.9 \pm 5.1$ & $48.2 \pm 4.6$ & $40.9 \pm 8.4$ \\
\hline
\end{tabular}

Effect of seminal plasma heparin binding proteins on in vitro capacitation and acrosome reaction

Spermatozoa exhibiting different stages of AR and IMMP are shown in Figs. 2 and 3, respectively. Motility, viability and high IMMP were significantly $(\mathrm{p}<0.05)$ high in G-I as compared to G-II at zero hr of incubation (Fig. 4-7).

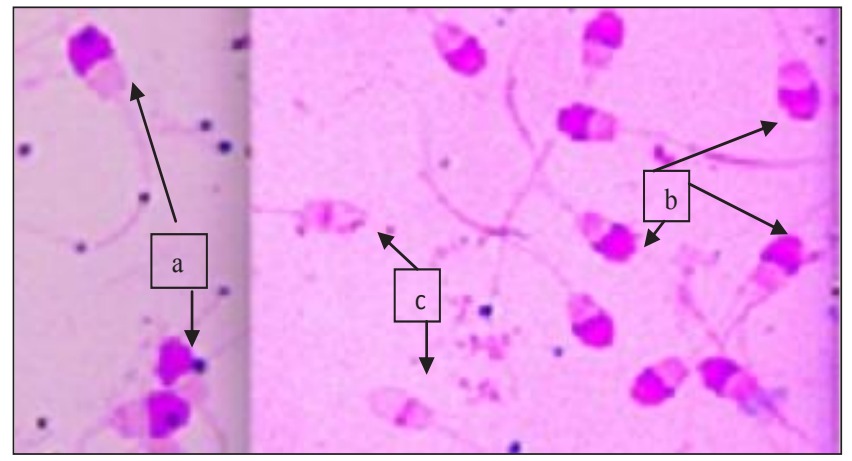

Fig. 2: Showing vesiculation and shedding of acrosome in beetal buck spermatiozoa. Spermatozoa with (a) intact, (b) vesiculted and (c) shedded acrosome

On the contrary, acrosome damage and medium IMMP were significantly $(\mathrm{p}<0.05)$ high in G-II as compared to G-I at zero hour of incubation. There was a significant $(\mathrm{p}<0.05)$ decrease in individual motility, viability and high IMMP from zero to six hrs of incubation in both control and HBP treated samples of both groups (Fis. 4-7). Decrease in motility and viability was higher in HBP treated (36.66 to $58.34 \%$ and 27.17 to
$33.38 \%$ ) compared to control (25.66 to $53.34 \%$ and 32.07 to $39.38 \%)$.

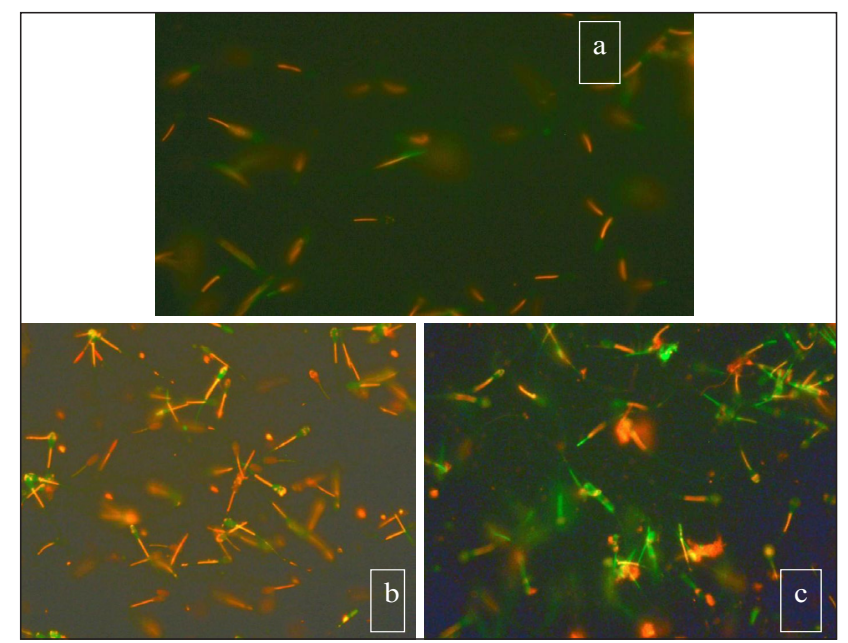

Fig. 3: Showing inner mitochondrial membrane potential of spermatozoa during in vitro capacitation and acrosome reaction. (a) $0 \mathrm{hr}$, (b) $4 \mathrm{hrs}$ and (c) 6 hrs of incubation. Mitochondria with orange, yellow and green fluoresence indicate high, medium and low mitochondrial membrane potential

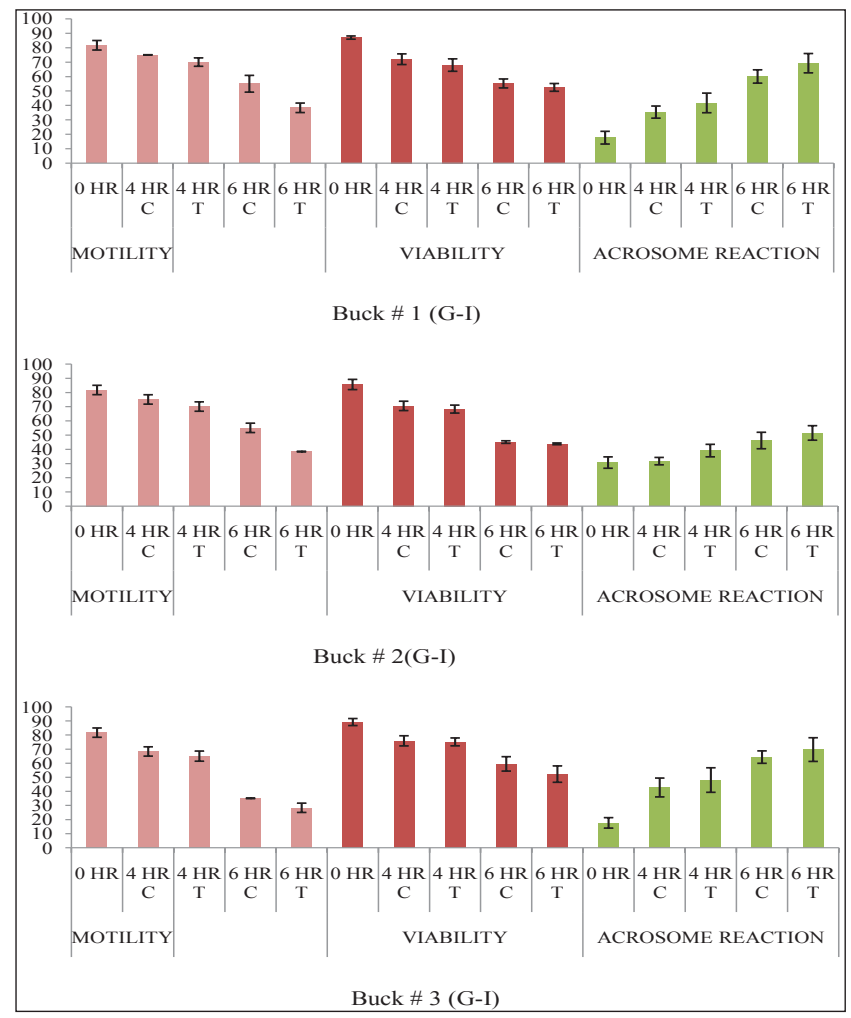

Fig. 4: Effect of SP-HBP on motility, viability and 
acrosome reaction during incubation of spermatozoa of buck \# 1, 2 and 3 (exhibiting > 80\% initial motility) at $37^{\circ} \mathrm{C}$ for $6 \mathrm{hrs}$

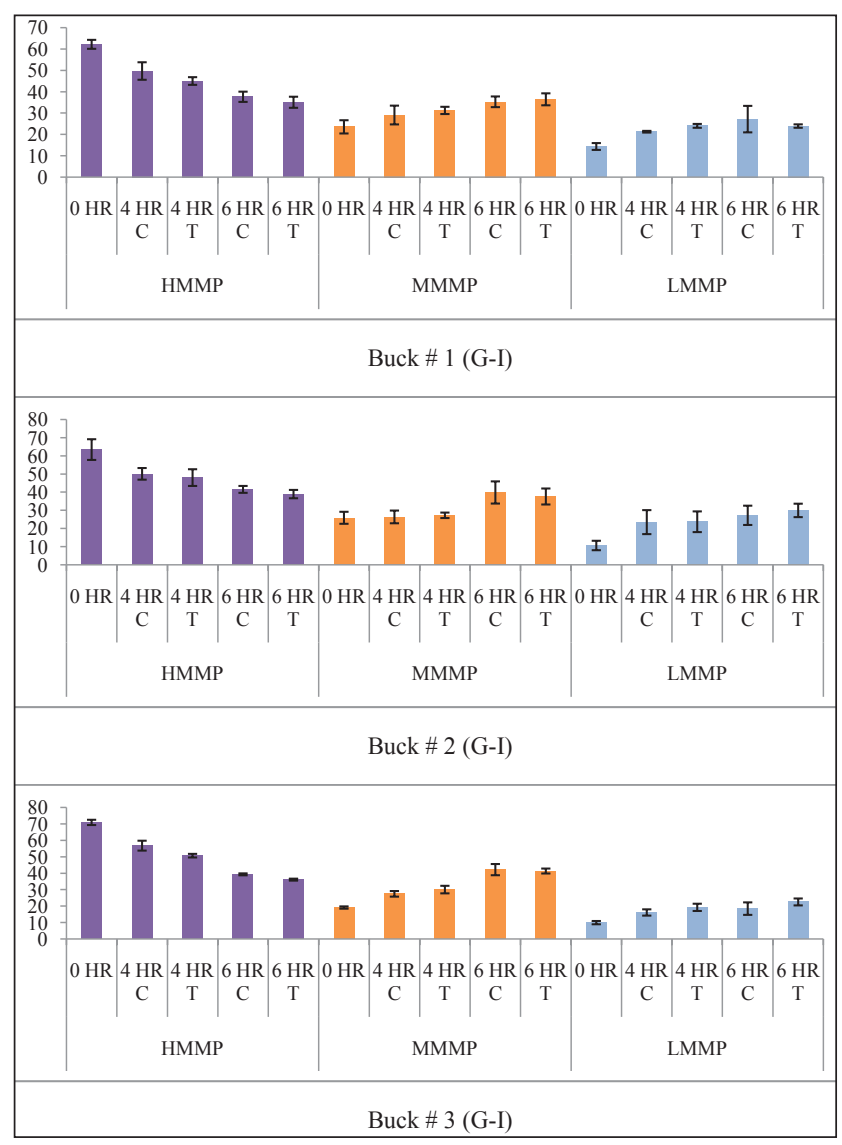

Fig. 5: Effect of SP-HBP on Inner mitochondrial membrane potential during incubation of spermatozoa of buck \# 1, 2 and 3 (exhibiting $>80 \%$ initial motility) at $37^{\circ} \mathrm{C}$ for $6 \mathrm{hrs}$

The more rapid decrease in motility and viability was also observed in bovine spermatozoa with $\mathrm{FF}$ and LD-FF fraction (Therien et al., 2001) compared to control. Decrease in motility was higher than viability in HBP treated as well as control samples. It may be hypothesized that once the spermatozoa are acrosome reacted, they lose the motility. Corresponding to motility and viability reduction, there was also decline in the high IMMP with increase in time of incubation. Mitochondrial function is usually highly correlated with viability assays (Kasai et al., 2002 and Marchetti et al., 2004).

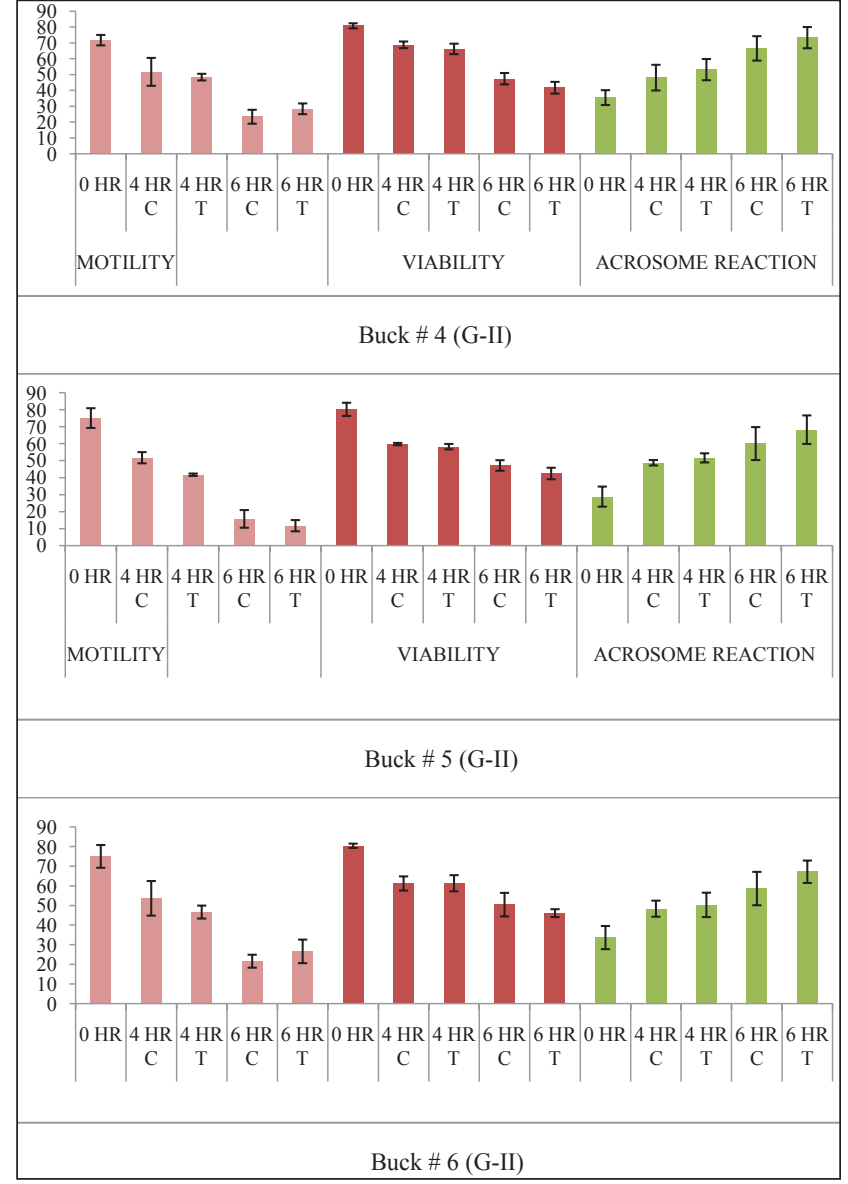

Fig. 6: Effect of SP-HBP on motility, viability and acrosome reaction during incubation of spermatozoa of buck \# 4, 5 and 6 (exhibiting < 80\% initial motility) at $37^{\circ} \mathrm{C}$ for $6 \mathrm{hrs}$

Mitochondrial respiration would be predominant source of ATP required for flagellar movement. Hence, sperm motility would indirectly reflect the ability of mitochondria to propel the sperm and represent a way to detect the ATP production. Determination of IMMP was done by JC-1 probe. Several reports suggest that analysis of IMMP may be also a mean to assess sperm motility and changes in IMMP could be a good indicator of sperm's functional status. A highly significant correlation between high IMMP and motility has been described in stallion and humans (Love et al., 2003 and Marchetti et al., 2002). In other words, it can be said that due to decrease in IMMP, there was 
a decrease in motility of spermatozoa during in vitro induction of capacitation/AR of goat buck spermatozoa. However, it was higher in the presence of SP-HBP.

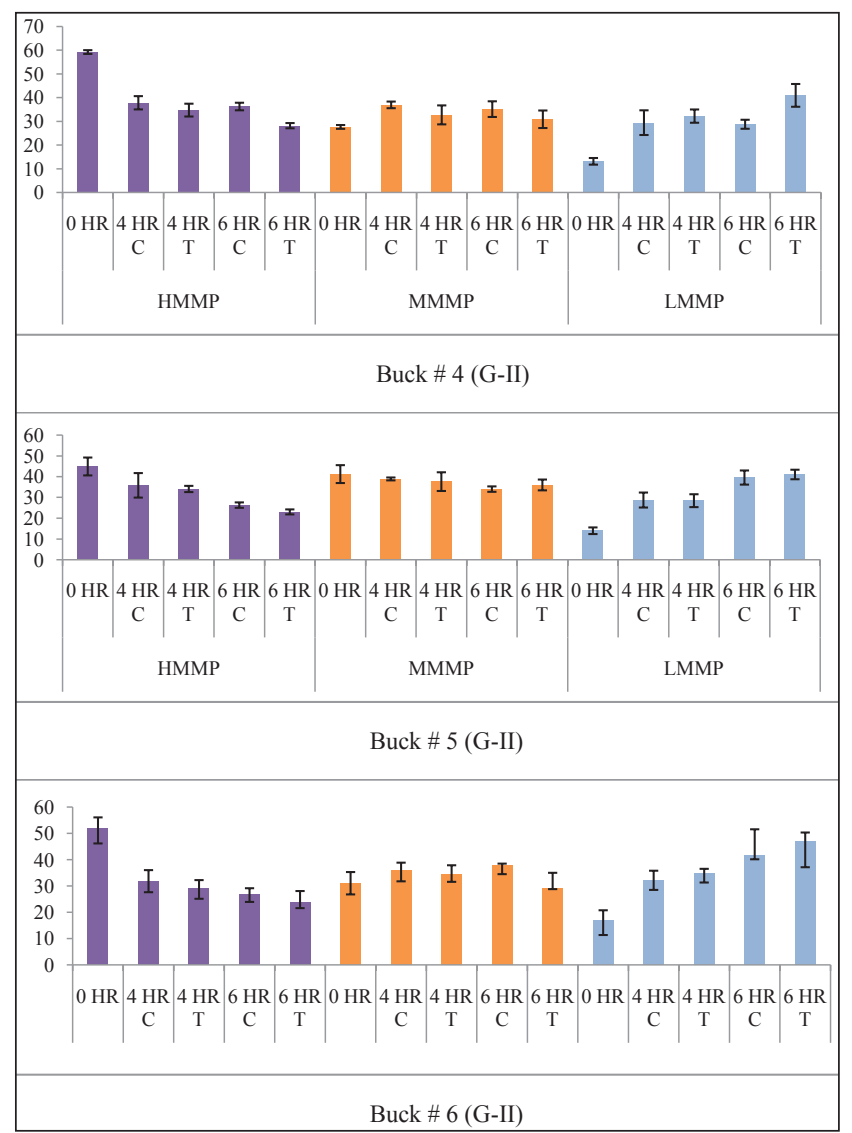

Fig. 7: Effect of SP-HBP on Inner mitochondrial membrane potential during incubation of spermatozoa of buck \# 4, 5 and 6 (exhibiting $<80 \%$ initial motility) at $37^{\circ} \mathrm{C}$ for $6 \mathrm{hrs}$.

A significant $(\mathrm{p}<0.05)$ increase in acrosome reaction (vesiculated and acrosome reacted spermatozoa) and medium IMMP was noticeable in control and HBP treated samples with an increase in incubation time (Figs. 4-7). Percentage of spermatozoa with vesiculated and acrosome reacted spermatozoa was higher in two bucks of G-I compared to G-II in control as well as HBP treated samples. It indicated that higher percentage of initial motility does not result in high rate of $\mathrm{AR}$. Rather, buck effect was noticeable on in vitro capacitation and AR in both groups. In vitro induced AR was also significantly $(\mathrm{p}<0.05)$ higher in HBP treated samples compared to control in both groups at $4 \mathrm{hrs}$ and $6 \mathrm{hrs}$ of incubation. Therefore, observations indicated that induction of capacitation and $\mathrm{AR}$ results in decrease in motility, viability and high IMMP.

During the present study, supplementation of HBP in the presence of $10 \mu \mathrm{g} / \mathrm{ml}$ heparin enhanced the in vitro AR rate. It has been determined in both in vivo and in vitro that heparin or GAGs capacitate spermatozoa, probably due to their ability to sequester coating proteins (Parrish et al., 1994). Due to this reason, these proteins are called as HBP. HBP are produced by the accessory glands under the control of androgens (Miller et al., 1990) and secreted within the SP (Nur et al., 2005). It is well documented in bovines that HBP bind the epididymal sperm and increase the ability of AR in response to heparin and other proteins of zona pellucida (Ax et al., 2002). Similar to our observation, significant difference in in vitro capacitation of SP-HBP treated and control group was observed in buffalo semen (Arangasamy et al., 2005).

Effect of SP-HBP on in vitro capacitation and AR of buck spermatozoa was revealed by a significant $(\mathrm{p}<0.05)$ increase of $6.79 \%$ and $7.90 \%$ in G-I and G-II, respectively. Patel et al. (2016) also revealed significant $(\mathrm{p}<0.05)$ increase of $6.2 \%$ to $11.4 \%$ in capacitated/acrosome reacted spermatozoa upon binding of SP-HBP to the sperm membrane. It indicated that incorporation of HBP to the buck spermatozoa also resulted in high rate of capacitation/AR. In bovine spermatozoa, capacitation is also modulated by phophatidyl choline binding protein of SP in the presence of heparin (Amman et al., 1999). Therien et al. (2001) reported that FF and FFHDL induced capacitation was increased by a pre-incubation with BSA - A1/A2 proteins in bovine epididymal spermatozoa. BSP proteins can modulate the capacitation process by two different mechanisms using either heparin or high-density lipoprotein (HDL) as capacitating 
agent (Lane et al., 1999). BSP proteins are reported to bind spermatozoa and also interact with a polipoprotein A1 which is a major component of HDL (Lane et al., 1999). Moreover, the HDL has been identified as a cholesterol acceptor and implicated in sperm capacitation and the AR of human sperm (Hamdi et al., 2010). Upon ejaculation, the BSP proteins interact with the sperm surface via their membrane choline phospholipids and induce sperm cholesterol efflux (Therien et al., 1995; Moreau et al., 1999; Lusignan et al., 2007). This leads to the sperm capacitation following subsequent interaction with heparin. BSP proteins bind to the sperm membrane and act as heparin receptors. This binding increases the heparin-binding sites on the sperm membrane. The binding of Heparin to the BSP proteins-coated sperm membrane induce a series of intracellular events such as an increase in $\mathrm{pH}, \mathrm{Ca}^{+2}$, and cAMP (Pons-Rejraji et al., 2009). Since, both heparin and SP-HBP were incorporated in the capacitation medium, therefore, the above proposed mechanism may seem responsible for enhanced rate of in vitro AR in SP-HBP treated semen of Beetal bucks.

Literature indicating effect of HBP on capacitation/AR of goat buck spermatozoa is lacking. However, a few reports indicated successful induction of in vitro capacitation/ AR of goat buck spermatozoa. The plasma membrane alterations accompanying in vitro capacitation and AR of goat buck spermatozoa were studied, which revealed fusion of plasma membrane and outer acrosomal membrane at multiple foci (Bawa et al., 1993). During the present study, $20.86 \%$ to $52.01 \%$ and $15.52 \%$ to $46.67 \%$ AR was induced in HBP treated and control samples after $6 \mathrm{hrs}$ of incubation. Incubation of mature goat spermatozoa in BSA free medium containing of $\beta$-cyclodextrin resuted in 35\% AR (Ibbora et al., 2000).

\section{Effect of HBP on lipid peroxidation during in vitro capacitation/AR}

Average MDA production ( $\mu \mathrm{M} / 10^{9}$ spermatozoa) was $28.83 \pm 3.41,32.30 \pm 2.24$ and $23.71 \pm 1.43$ in freshly ejaculated, HBP induced and without HBP induced acrosome reacted spermatozoa, respectively (Table 2). It indicated a nonsignificant $(p>0.05)$ increase in LPO during capacitation and AR of buck spermatozoa. Spermatozoa itself, produce small amounts of ROS that are essential to many of physiological processes i.e. capacitation, hyper-activation and oocyte fusion (Aitken et al., 1998). Low levels of ROS are also shown to be essential for fertilization. Therefore, it can be revealed that higher levels of MDA in capacitated and acrosome reacted spermatozoa was essential for the induction of capacitation and AR. MDA level was non-significantly ( $p>0.05$ ) less in HBP treated spermatozoa as compared

Table 2: Effect of heparin binding proteins on lipid peroxidation (MDA, $\mu \mathrm{M} / 109$ spermatozoa) during in vitro capacitation and acrosome reaction of goat buck spermatozoa

\begin{tabular}{cccc}
\hline \multirow{2}{*}{ Buck No. } & \multicolumn{3}{c}{ Spermatozoa } \\
\cline { 2 - 4 } & Ejaculated & Capacitated /AR & HBP treated, Capacitated /AR \\
\hline 1 & $25.24^{\mathrm{a}} \pm 2.89$ & $32.75^{\mathrm{a}} \pm 2.11$ & $24.76^{\mathrm{a}} \pm 2.40$ \\
2 & $15.27^{\mathrm{a}, \mathrm{b}} \pm 3.74$ & $29.58^{\mathrm{a}} \pm 6.47$ & $22.41^{\mathrm{a}} \pm 7.07$ \\
3 & $24.58^{\mathrm{a}} \pm 2.17$ & $35.58^{\mathrm{a}} \pm 6.99$ & $24.10^{\mathrm{a}} \pm 2.91$ \\
4 & $33.00^{\mathrm{a}} \pm 3.45$ & $27.69^{\mathrm{b}} \pm 3.54$ & $20.34^{\mathrm{b}} \pm 2.57$ \\
5 & $27.80^{\mathrm{a}} \pm 3.98$ & $30.61^{\mathrm{a}} \pm 3.12$ & $23.31^{\mathrm{a}} \pm 3.72$ \\
6 & $47.11^{\mathrm{a}, \mathrm{c}} \pm 16.02$ & $37.59^{\mathrm{a}} \pm 10.12$ & $27.34^{\mathrm{a}} \pm 2.49$ \\
Total & $28.83^{\mathrm{a}} \pm 3.41$ & $32.30^{\mathrm{a}} \pm 2.24$ & $23.71^{\mathrm{a}} \pm 1.43$ \\
\hline
\end{tabular}

Figures in superscripts indicate significant $(a, b, c)$ and non-significant differences $(a, a)$ among the bucks and treatments. 
to control samples. However, rate of AR was significantly $(\mathrm{p}<0.05)$ higher in HBP treated spermatozoa compared to control. Although, small amounts of ROS are required for several sperm functions, but excessive levels may have negative impact on the quality of spermatozoa and impair the fertilizing capacity (Tvrdaet al., 2011). Therefore, reduced levels of ROS in HBP treated spermatozoa may be responsible for higher rate of AR in comparison to control. These observations also reveal that LPO can be an indicator of in vitro capacitation and AR of buck spermatozoa.

\section{CONCLUSIONS}

Study highlighted significance of SP-HBP on in vitro capacitation / AR of buck spermatozoa. Since, capacitation/AR is pre-requisite for fertilization, therefore, roll of HBP in higher fertility rate of goat buck semen may also be predicted in goat bucks.

\section{ACKNOWLEDGEMENTS}

Authors are thankful to Department of Livestock Production and Management, Guru Angad Dev Veterinary and Animal Sciences University, Ludhiana for providing semen samples.

\section{REFERENCES}

Aitken, R.J., Gordon, E., Harkiss, D., Twigg, J.P., Milne, P., Jennings, Z. and Irvine, D.S. 1998. Relative impact of oxidative stress on the functional competence of genomic integrity of human spermatozoa. Bio. Reprod., 59: 1037-46.

Arangasamy, A., Singh, L.P., Ahmed, N., Ansari, M.R. and Ram, G.C. 2005. Isolation and characterization of heparin and gelatin binding buffalo seminal plasma proteins and their effect on cauda epididymal spermatozoa. Ani. Reprod. Sci., 90: 243-54.

Ax, R.L., Hawkins, H.E., De Nise, S.K., Holm, T.R. and Zhang, H.M. 2002. New developments in managing the bull. Factors Affecting calf crop: Biotechnology of reproduction $\left(1^{\mathrm{ed}}\right)$. CRC Press LLC, Florida, USA, pp. 120-48.
Bawa, S.R., Pabst, M.A., Werner, G. and Bains, H.K. 1993. Capacitated and acrosome reacted spermatozoa of goat (Capra indicus): a fluorescence and electron microscopic study. Andrologia., 25: 123-35.

Buege, J.A. and Steven, A.D. 1978. Microsomal lipid peroxidation methods. Enzymology, 52: 302-10.

Cormier, N.and Bailey, J.L. 2003. A differential mechanism is involved during heparin- and cryopreservation-induced capacitation of bovine spermatozoa. Biol. Reprod., 69: 177-85.

Dhillon, N.S., Cheema, Ranjna, S. and Kaswan, S. 2019. Seasonal variations in sperm characteristics, antioxidant defense system, seminal plasma testosterone and total proteins of beetal goat bucks. Ind. J. Small Rum. Res., Accepted.

Farooqui, A.A. 1980. Purification of enzymes by heparin-sepharose affinity chromatography. $J$. Chromat., 184: 335-45.

Hamdi, S.M., Vieitez, G., Jaspard, B., Barbaras, R., Perret, B., Mieusset, R., Parinaud, J. and Collet, X. 2010. Effects of human follicular fluid and high-density lipoproteins on early spermatozoa hyperactivation and cholesterol efflux. J. Lip. Res., 51: 1363-69.

Iborra, A., Companyo, M., Martınez, P. and Morros, A. 2000. Cholesterol Efflux Promotes Acrosome Reaction in Goat Spermatozoa. Biol. Reprod., 62: 378-83.

Kasai, T., Ogawa, K., Mizuno, K., Nagai, S., Uchida, Y., Ohta, S., Fujie, M., Suzuki, K., Hirata, S and Hoshi, K. 2002. Relationship between sperm mitochondrial membrane potential, sperm motility and fertility potential. Asian J. Androl., 4: 97-103.

Lane, M. Therien, I. Moreau, R. and Manjunath, P. 1999. Heparin and highdensity lipoprotein mediate bovine sperm capacitation by different mechanisms. Biol. Reprod., 60: 169-75.

Lowry, O.H., Rosenberg, N.J., Farr, A.L. and Randall, R.J. 1951. Protein measurement with the folin phenol reagent. J. Biol. Chem., 193: 265-75.

Love, C.C., Thompson, J.A., Brinsko, S.P., Rigby, S.L., Blanchard, T.L., Lowry, V.K. and Varner DD. 2003. Relationship between stallion sperm motility and viability as detected by two fluorescence staining techniques using flow cytometry. Theriogenology, 60:1127-38.

Lusignan, M.F., Bergeron, A., Crête, M.H., Lazure, C. and Manjunath, P. 2007. Induction of epididymal 
boar sperm capacitation by $\mathrm{pB} 1$ and BSP-A1/-A2 proteins, members of the BSP protein family. Biol. Reprod., 76: 424-32.

Manaskova, P., Liberda, J., Ticha, M. and Jonakova, V. 2002. Isolation of nonheparin-binding and heparin-binding proteins of boar prostate. $J$. Chromatography, 770: 137-43.

Marchetti, C., Obert, G., Defossez, A., Formstecher, P. and Marchetti, P. 2002. Study of mitochondrial membrane potential, reactive oxygen species, DNA fragmentation and cell viability by flow cytometry in human sperm. Human Reprod., 17: 1257-65.

Marchetti, C., Jouy, N., Leroy-Martin, B., Defossez, A., Formstecher, P. and Marchetti, P. 2004. Comparison of four fluorochromes for the detection of the inner mitochondrial membrane potential in human spermatozoa and their correlation with sperm motility. Hum. Reprod., 19: 2267-76.

Miller, D.J., Winer, M.A. and Ax, R.L. 1990. Heparin binding proteins from seminal plasma bind to bovine spermatozoa and modulate capacitation by heparin. Bio. Reprod., 42: 899-15.

Moreau, R., Frank, P.G., Perreault, C., Marcel, Y.L. and Manjunath, P. 1999. Seminal plasma choline phospholipid-binding proteins stimulate cellular cholesterol and phospholipid efflux. Biochem. Biophys. Acta., 1438: 38-46.

Nur, Z., Dogan, I., Gunay, U. and Soylu, A.K. 2005. Relationships between sperm membrane integrity and other semen quality characteristics of the semen of Saanen goat bucks. Bul. Vet. Inst. Pulawy., 49: 183-87.
Parrish, J.J., Susko-Parrish, J., Winer, M.A. and First, N.L. 1988. Capacitation of bovine sperm by heparin. Biol. Reprod., 38: 1171-80.

Patel, M., Gandotra, V.K., Cheema, Ranjna S., Bansal, A.K. and Kumar, A. 2016. Seminal Plasma Heparin Binding Proteins Improve Semen Quality by Reducing Oxidative Stress during Cryopreservation of Cattle Bull Semen. Asian Austral J. Ani. Sci., 9: 1247-1255.

Pons-Rejraji, H., Bailey, J.L. and Leclerc, P. 2009. Modulation of bovine sperm signalling pathways: correlation between intracellular parameters and sperm capacitation and acrosome exocytosis. Reprod. Fert. Dev., 21: 511-24.

Singh, A.K., Brar, P.S. and Cheema Ranjna, S. 2016. Effect of purified seminal plasma heparin binding proteins on in vitro acrosome reaction of frozenthawed buffalo bull semen. Ind. Vet. J., 93: 69-70.

Therien, I., Moreau, R. and Manjunath, P. 2001. Effect of seminal phospholipid-binding proteins and follicular fluid on bovine sperm capacitation. Bio. Reprod., 65: 41-51.

Tvrda, E., Knazicka, Z., Bardos, L., Massanyi, P. and Lukac, N. 2011. Impact of oxidative stress on male fertility-A review. Acta. Vet. Hung., 59: 465-84. 
